\title{
URBANISMO NA PERIFERIA DO MUNDO GLOBALIZADO metrópoles brasileiras
}

\author{
Ermínia Maricato \\ Professora e Coordenadora da Pós-Graduação da Faculdade de Arquitetura e Urbanismo da USP. \\ Ex-Secretária de Habitação e Desenvolvimento Urbano do Município de São Paulo. \\ Autora do livro A cidade do pensamento único.
}

\begin{abstract}
Resumo: O texto enfoca o processo de urbanização no Brasil a partir de alguns indicadores demográficos (mortalidade infantil, expectativa de vida média, fertilidade feminina), socioeconômicos (crescimento, renda, desemprego e violência) e urbanísticos (crescimento urbano e crescimento de favelas), de modo a evidenciar um quadro controverso marcado por positividades e negatividades. Diversos autores são consultados para buscar a explicação desse quadro. A urbanização da sociedade brasileira se deu no século XX, mas carrega todo o peso da "formação" da sociedade caracterizada como "defasagem e continuidade".

Palavras-chave: urbanização; industrialização; indicadores sociais.
\end{abstract}

A urbanização da sociedade brasileira tem constituído, sem dúvida, um caminho para a modernização, mas, ao mesmo tempo, vem contrariando aqueles que esperavam ver, nesse processo, a superação do Brasil arcaico, vinculado à hegemonia da economia agroexportadora. O processo de urbanização recria o atraso a partir de novas formas, como contraponto à dinâmica de modernização. As características do Brasil urbano impõem tarefas desafiadoras, e os arquitetos e planejadores urbanos não têm conhecimento acumulado nem experiência para lidar com elas. A dimensão da tragédia urbana brasileira está a exigir o desenvolvimento de respostas que devem partir do conhecimento da realidade empírica para evitar a formulação das "idéias fora do lugar" tão características do planejamento urbano no Brasil (Maricato et alii, 2000).

O objetivo deste texto é contribuir para um maior conhecimento da realidade brasileira e para o desmonte das construções ideológicas presentes, tanto nas representações sobre as nossas cidades quanto nos planos mágicos que nos propõem outros saltos para o futuro, além daqueles que uma parcela da sociedade brasileira já deu, buscando atalhos e ignorando o destino da maior parte da população restante.

O Brasil, como os demais países da América Latina, apresentou intenso processo de urbanização, especialmente na segunda metade do século XX. Em 1940 a população urbana era de $26,3 \%$ do total. Em 2000 ela era de $81,2 \%$. Esse crescimento se mostra mais impressionante ainda se lembrarmos os números absolutos: em 1940 a população que residia nas cidades era de 18,8 milhões de habitantes, e em 2000 ela era de aproximadamente 138 milhões. Constatamos, portanto, que em 60 anos os assentamentos urbanos foram ampliados de forma a abrigar mais de 125 milhões de pessoas. Considerando apenas a última década do século XX, as cidades brasileiras aumentaram em 22.718.968 pessoas. Isso significa mais da metade da população do Canadá ou um terço da população da França.

Trata-se de um gigantesco movimento de construção urbana necessário para o assentamento residencial dessa população, bem como para a satisfação de suas necessidades de trabalho, abastecimento, transporte, saúde, energia, água, etc. Ainda que o rumo tomado pelo crescimento urbano não tenha respondido satisfatoriamente a todas essas necessidades, o território foi ocupado e foram geradas condições para viver nesse espaço. Bem ou mal, de algum modo, todos esses 138 milhões de habitantes moram em cidades.

Vamos lembrar rapidamente alguns marcos históricos relacionados a esse crescimento urbano. O Brasil deixa o século XIX com aproximadamente $10 \%$ da população nas cidades (Santos, M. 1993). Considerando o universo das Américas, o Brasil já apresentava cidades de grande porte desde o período colonial, mas é somente a partir da virada do século XIX e das primeiras décadas do século XX que o processo de urbanização da sociedade começa real- 
mente a se consolidar, impulsionado pela emergência do trabalhador livre, pela Proclamação da República e por uma indústria ainda incipiente que se desenrola na esteira das atividades ligadas à cafeicultura e às necessidades básicas do mercado interno.

As reformas urbanas, realizadas em diversas cidades brasileiras entre o final do século XIX e início do século $\mathrm{XX}$, lançaram as bases de um urbanismo moderno "à moda" da periferia. Eram feitas obras de saneamento básico e embelezamento paisagístico, implantavam-se as bases legais para um mercado imobiliário de corte capitalista, ao mesmo tempo em que a população excluída desse processo era expulsa para os morros e as franjas da cidade. Manaus, Belém, Porto Alegre, Curitiba, Santos, Recife, São Paulo e especialmente o Rio de Janeiro são cidades que passaram, nesse período, por mudanças que conjugaram saneamento ambiental, embelezamento e segregação territorial.

A economia mantém seu epicentro no setor agrário exportador até 1930, quando ocorre o que Florestan Fernandes denomina a revolução burguesa no Brasil: o Estado investindo decididamente em infra-estrutura para o desenvolvimento industrial visando à substituição de importações. A burguesia industrial assume a hegemonia política na sociedade sem que se verifique uma ruptura com os interesses hegemônicos. Essa ambigüidade entre ruptura e continuidade, verificada em todos os principais momentos de mudança na sociedade brasileira, marcará o processo de urbanização com as raízes da sociedade colonial, embora ele ocorra em pleno século XX, quando formalmente o Brasil é uma República independente. A questão fundiária, que ocupou um lugar central nos conflitos vividos pelo país no século XIX, referia-se fundamentalmente ao campo. A crescente generalização da propriedade privada da terra a partir de 1850 - com a confirmação do poder político dos grandes proprietários nas décadas seguintes - e a emergência do trabalho livre a partir de 1888 (acontecimentos que estão interligados, como já foi demonstrado por muitos autores) ocorreram antes da urbanização da sociedade. No entanto, a urbanização foi fortemente influenciada por esses fatores: a importância do trabalho escravo (inclusive para a construção e manutenção dos edifícios e das cidades), a pouca importância dada à reprodução da força de trabalho, mesmo com a emergência do trabalhador livre, e o poder político relacionado ao patrimônio pessoal.

Mesmo assim, não há como não reconhecer que a industrialização que se afirma a partir de 1930 e vai até o fim da Segunda Guerra Mundial constituiu um caminho de avanço relativo de forças espontâneas e de fortalecimento do mercado interno, com grande desenvolvimento das forças produtivas, diversificação, assalariamento crescente e modernização da sociedade, como nota Caio Prado - um dos pensadores que enfatizam a relação entre a consolidação do mercado interno e a construção da nação, relação essa que, entretanto, era fortemente constrangida pela desigualdade regional. Mas essa "construção autônoma da nação" é interrompida pelo rearranjo por que passa o processo brasileiro de industrialização após o fim da Segunda Guerra, quando se verifica sobre ele um significativo e crescente controle do capital internacional. ${ }^{1}$

Em 1950 o processo de industrialização entra em nova etapa. O país passa a produzir bens duráveis e até mesmo bens de produção. Para Celso Furtado, com essa "nova dependência" o centro das decisões não é mais interno ao país e nem tem o mercado nacional como seu epicentro. A dependência se aprofunda, bem como a inserção subalterna do país na divisão internacional do trabalho.

Além dos inúmeros eletrodomésticos e bens eletrônicos, o automóvel produzido por essa grande indústria fordista promove, a partir dos anos 50, mudanças significativas no modo de vida dos consumidores (que inicialmente eram restritos às faixas de maior renda) e também na habitação e nas cidades. Com a massificação do consumo dos bens modernos, dos eletroeletrônicos e também do automóvel, mudam radicalmente o modo de vida, os valores, a cultura e o conjunto do ambiente construído. Da ocupação do solo urbano até o interior da moradia, a transformação foi profunda, o que não significa que tenha sido homogeneamente moderna. Ao contrário, os bens modernos passam a integrar um cenário em que a prémodernidade sempre foi muito marcante, especialmente na moradia ou no padrão de urbanização dos bairros da periferia (Maricato, 1996).

O grau de dependência externa (se é que podemos medir a maior ou menor independência para enxergar a realidade social interna e reagir a ela) interfere decisivamente na produção do ambiente construído. Caio Prado Jr. tem, entre muitas virtudes, a de chamar atenção, de forma pioneira, sobre a predação ambiental que acompanha cada ciclo econômico brasileiro. Além de utilizar os melhores esforços e a energia do país, que restam imobilizados e abandonados quando o produto que é objeto desse movimento deixa de ser demandado pelo mercado externo, o território também é arrasado, como acontece com o ciclo da cana, do ouro, do café, etc. (Prado Jr., 1990). 
Celso Furtado destaca o caráter predatório dessa industrialização, que, diante do infraconsumo da maior parte da população, implanta no país um modelo baseado na obsolescência programada, no desperdício, na substituição de produtos que é própria dos países altamente desenvolvidos (Furtado, 1959).

De 1940 a 1980, o PIB brasileiro cresceu a índices superiores a 7\% ao ano, um dos maiores do mundo no período. A riqueza gerada nesse processo permaneceu bastante concentrada, como veremos, embora, mesmo com a concentração da renda, o alto grau do crescimento econômico tenha influído na melhora de vida de toda a população, especialmente daquela que abandonou o campo buscando melhores condições de vida nas cidades.

É com o Banco Nacional da Habitação integrado ao Sistema Financeiro da Habitação, criados pelo regime militar a partir de 1964, que as cidades brasileiras passam a ocupar o centro de uma política destinada a mudar seu padrão de produção. A drenagem de recursos financeiros para o mercado habitacional, em escala nunca vista no país, ocasiona a mudança no perfil das grandes cidades, com a verticalização promovida pelos edifícios de apartamentos. A introdução do apartamento como principal forma de moradia da classe média tem início na década de 40 , em Copacabana, no Rio de Janeiro. Mas é com a implementação do SFH - Sistema Financeiro da Habitação -, em 1964, que o mercado de promoção imobiliária privada, baseado no edifício de apartamentos, consolida-se por meio de uma explosão imobiliária. Além da imagem das cidades, mudam também o mercado fundiário e vários aspectos da cadeia produtiva (que, apesar disso, não abandona suas características de atraso em relação ao processo de trabalho) (Ribeiro, 1997; Castro, 1999).

Infelizmente o financiamento imobiliário não impulsionou a democratização do acesso à terra por meio da instituição da função social da propriedade. Essa era a proposta da reforma urbana preconizada pelos arquitetos no Congresso do IAB - Instituto de Arquitetos do Brasil de 1963. A atividade produtiva imobiliária não subjugou as atividades especulativas, como ocorreu nos países centrais do capitalismo. O mercado não se abriu para a maior parte da população que buscava moradia nas cidades. Ele deu absoluta prioridade às classes médias e altas.

Por outro lado, as iniciativas de promoção pública os conjuntos habitacionais populares - também não enfrentaram a questão fundiária urbana, como bem mostra Silva em sua tese de doutorado (Silva, 1998). Os governos municipais e estaduais desviaram sua atenção dos vazios urbanos (que, como se sabe, se valorizam com os investimentos públicos e privados feitos nos arredores) para jogar a população em áreas completamente inadequadas ao desenvolvimento urbano racional, penalizando seus moradores e também todos os contribuintes que tiveram de arcar com a extensão da infra-estrutura (Maricato, 1987).

O SFH alimentou também a extensão das obras (ou megaobras) de saneamento - particularmente a extensão do serviço de água tratada - ao mesmo tempo em que as obras viárias locais e regionais foram custeadas, principalmente pelos orçamentos estaduais e municipais. Na segunda metade dos anos 70, as atividades ligadas à construção civil ajudaram a manter o significativo crescimento do PIB, que já dava sinais de desaceleração (Maricato, 1987).

Enquanto o crescimento econômico se manteve alto, o modelo "funcionou" criando uma nova classe média urbana, mas mantendo grandes contingentes sem acesso a direitos sociais e civis básicos: legislação trabalhista, previdência social, moradia e saneamento, entre outros. A recessão que se seguiu nos anos 80 e 90 - quando as taxas de crescimento demográfico superaram as do crescimento do PIB, fazendo com que a evolução do PIB per capita fosse negativa na década de 80 - trouxe um forte impacto social e ambiental, ampliando o universo de desigualdade social. Nessas décadas, conhecidas como "décadas perdidas", a concentração da pobreza é urbana. Pela primeira vez em sua história, o Brasil tem multidões concentradas em vastas regiões - morros, alagados, várzeas ou mesmo planícies - marcadas pela pobreza homogênea. Nos anos 80 a sociedade brasileira conheceu também, pela primeira vez, um fenômeno que ficaria conhecido como violência urbana: o início de uma escalada de crescimento do número de homicídios, sem precedentes na história do país.

As décadas perdidas não são as únicas a registrar as origens do que podemos chamar de tragédia urbana brasileira - enchentes, desmoronamentos, poluição dos recursos hídricos, poluição do ar, impermeabilização da superfície do solo, desmatamento, congestionamento habitacional, retorno de epidemias, violência, etc. O crescimento urbano sempre se deu com exclusão social, desde a emergência do trabalhador livre na sociedade brasileira, quando as cidades passam a ganhar nova dimensão e tem início o problema da habitação. Quando o trabalho se torna mercadoria, a reprodução do trabalhador deve ocorrer pelo mercado. Mas isso não se deu no começo do século XX, como não acontece até o seu final. Como previu Joaquim Nabuco, o peso do escravismo estaria presente, 
na sociedade brasileira, muito após sua abolição. Não só grande parte dos trabalhadores atua hoje fora do mercado formal, como, mesmo aquela regularmente empregada na moderna indústria fordista, apela para expedientes de subsistência para se prover de moradia na cidade. Isso significa que grande parte da população, inclusive parte daquela regularmente empregada, constrói sua própria casa em áreas irregulares ou simplesmente invadidas.

O modo de vida da maior parte da população urbana ao evidenciar a convivência dos bens modernos e até mesmo do automóvel particular (de segunda ou terceira mão) com o ambiente de um casebre cuja construção parece remontar a uma era pré-moderna - leva à conclusão de que não é possível dissociar esse urbano e essa moradia dessa sociedade e desse modelo de industrialização e desenvolvimento. $^{2}$

A tragédia urbana brasileira não é produto das décadas perdidas, portanto. Tem suas raízes muito firmes em cinco séculos de formação da sociedade brasileira, em especial a partir da privatização da terra (1850) e da emergência do trabalho livre (1888).

Uma vasta bibliografia trata da característica espacialmente concentradora da urbanização no Brasil bem como em toda a América Latina. O inchamento das cidades que não desenvolveram suficientemente sua capacidade produtiva para atender com emprego à população imigrante, que acaba relegada ao terciário informal -, a "desarticulação da rede urbana" com a formação de megapólos desproporcionais, o "tecido urbano truncado", entre outros tópicos, são teses e conceitos que não disfarçam a matriz em relação à qual o desvio é apontado (Castells, 1973). Imperialismo, dependência, fordismo periférico, de alguma forma a "macrocefalia" deve ser explicada. Para o que interessa aqui, iremos apenas constatá-la.

Dos quase 170 milhões de habitantes brasileiros em 2000 , aproximadamente $30 \%$ moram em nove metrópoles. Duas delas estão entre as maiores cidades do mundo: Rio de Janeiro (10,5 milhões de habitantes) e São Paulo (16,7 milhões). Um total de 13 cidades têm mais de um milhão de habitantes (Tabela 1).

\section{NOVIDADES NO PADRÃO DE URBANIZAÇÃO}

O padrão de urbanização brasileiro apresenta, a partir dos anos 80, mudanças que merecem algum destaque. Embora as metrópoles continuem crescendo proporcionalmente mais que o país, o ritmo desse crescimento diminuiu. As cidades de porte médio, com população entre 100 mil e 500 mil habitantes, crescem a taxas maiores do que as metrópoles nos anos 80 e 90 (4,8\% contra 1,3\%). Isso significa uma mudança radical no padrão de concentração metropolitana? Ainda não, pois, de um lado, as cidades de porte médio abrigam apenas, aproximadamente, $20 \%$ da população do país e, de outro, como mostra a Tabela 1, várias metrópoles ainda crescem a taxas altas: Brasília, Curitiba e Goiânia. Outras cidades que não aparecem nessa tabela, especialmente aquelas situadas nas regiões de recepção do fluxo migratório mais intenso como é o caso do norte e do centro-oeste do país -, apresentam crescimento muito superior ao das metrópoles ci-

TABELA 1

Cidades com Mais de 1 Milhão de Habitantes

Brasil - 1980-1996

\begin{tabular}{lccc}
\hline Metrópoles & $\begin{array}{c}\text { População }-1996 \\
\text { (em milhões) }\end{array}$ & $\begin{array}{c}\text { Taxa de Crescimento Anual } \\
1980 \text { a 1991 (\%) }\end{array}$ & $\begin{array}{c}\text { Taxa de Crescimento Anual } \\
1991 \text { a 1996 (\%) }\end{array}$ \\
\hline 1 São Paulo & 16.667 & 1,89 & 1,45 \\
2 Rio de Janeiro & 10.532 & 1,03 & 0,77 \\
3 Belo Horizonte & 3.829 & 2,53 & 2,00 \\
4 Porto Alegre & 3.292 & 2,59 & 1,43 \\
5 Recife & 3.258 & 1,80 & 1,10 \\
6 Salvador & 2.776 & 3,09 & 1,59 \\
7 Fortaleza & 2.639 & 3,51 & 2,35 \\
8 Brasilia & 2.354 & 3,55 & 3,69 \\
9 Curitiba & 2.349 & 3,04 & 3,43 \\
10 Campinas & 1.992 & 3,48 & 2,29 \\
11 Belém & 1.629 & 3,04 & 2,39 \\
12 Goiânia & 1.417 & 3,67 & 2,30 \\
13 Manaus & 1.157 & 4,58 & 2,73 \\
\hline
\end{tabular}

Fonte: IPEA. 
tadas. Apesar dessa observação, a aceleração extraordinária do crescimento das cidades de porte médio e das cidades litorâneas de um modo geral exige, evidentemente, atenção.

É preciso considerar ainda que as periferias das metrópoles cresceram mais do que os núcleos centrais, o que implica um aumento relativo das regiões pobres. Das 12 regiões metropolitanas, os municípios centrais cresceram em média 3,1\% entre 1991 e 1996, enquanto os municípios periféricos cresceram $14,7 \%$. Dessas metrópoles, as periferias que mais se expandiram, no período, foram: Belém (157,9\%), Curitiba (28,2\%), Belo Horizonte $(20,9 \%)$, Salvador $(18,1 \%)$ e São Paulo (16,3\%) (Ipea, 1999). Em algumas metrópoles, a diminuição do crescimento dos centros transformou-se em crescimento negativo dos bairros centrais. Há estudos que evidenciam essa dinâmica em São Paulo e no Rio de Janeiro (Silva, 1998). Em Belém, é o município central como um todo que apresenta crescimento negativo em contraposição ao gigantesco aumento dos municípios periféricos.

Outra mudança importante da dinâmica demográfica, que afeta o padrão de urbanização, diz respeito à diminuição do crescimento populacional devido, principalmente, à diminuição da taxa de natalidade, ou seja, ao decréscimo do número de filhos das mulheres em idade fértil. Poucos países apresentaram uma queda tão grande da taxa de natalidade em tão curto período histórico. Entre 1940 e 2000, essa taxa passa de 44,4 para 22,2 . Isso significa uma variação da média de 4,4 para 2,2 filhos para a mulher em idade fértil. No Gráfico 1 e na Tabela 2, é mostrada a evolução da taxa de natalidade entre 1940 e 2000 e da taxa de incremento populacional entre 1960 e 2000.

\section{TABELA 2}

Taxa Média de Incremento Anual da População Brasil - 1960-1991

Em porcentagem

\begin{tabular}{lccc}
\hline \multirow{2}{*}{ Anos } & \multicolumn{3}{c}{ Taxa Média de Incremento da População } \\
\cline { 2 - 4 } & Total & Urbana & Rural \\
\hline $1960 / 1970$ & 2,9 & 5,2 & 0,6 \\
$1970 / 1980$ & 2,5 & 4,4 & 0,6 \\
$1980 / 1990$ & 1,9 & 3,0 & $-0,6$ \\
$1991 / 2000$ & 1,6 & 2,5 & $-1,2$ \\
\hline
\end{tabular}

Fonte: Desep; Fundação IBGE.
GRÁFICO 1

Taxas de Natalidade

Brasil - 1940-2000

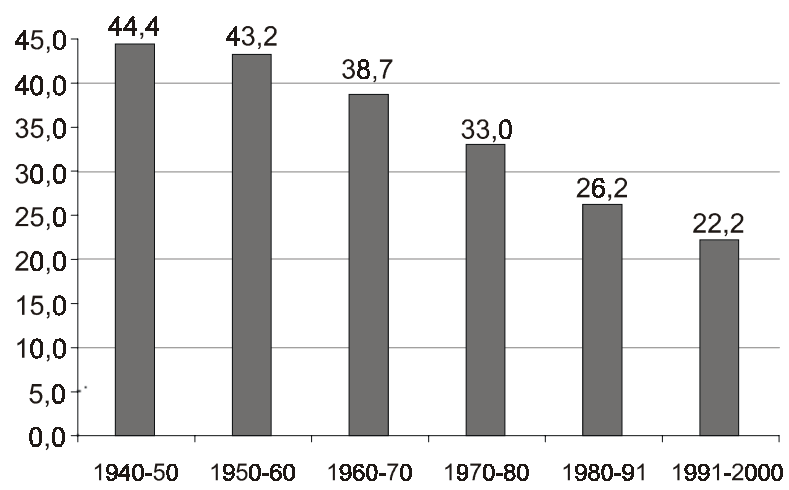

Fonte: Fundação IBGE.

\section{O PROCESSO DE URBANIZAÇÃO E A EVOLUÇÃO DE INDICADORES SOCIAIS}

Entre os indicadores que evoluíram positivamente nos últimos 50 anos no Brasil estão o da mortalidade infantil e o da esperança de vida ao nascer. Em 1940 o país apresentava uma taxa de 149 mortes entre mil nascidos vivos, antes de atingir um ano de idade. Em 1996 essa taxa foi de 50. A significativa diminuição do índice num período relativamente curto, que pode ser verificada no gráfico 2 , está relacionada, especialmente, à extensão da rede pública de água, às campanhas de vacinação e ao atendimento às gestantes.

Quanto à expectativa de vida ao nascer, o país apresentava a média nacional de 42,7 anos em 1940 e de 67 anos em 1996. É um espetacular acréscimo de anos de vida média.

Essa significativa melhora de indicadores não os torna homogêneos se consideradas as diversas regiões no Brasil. Nas áreas mais pobres, especialmente no Nordeste, os índices evoluem positivamente, mas mantêm uma diferença negativa em relação à média nacional. Em 1940, por exemplo, a esperança de vida ao nascer na Região Nordeste era de 38,4 anos, quando a média nacional era de 42,7. De qualquer modo, há uma notável e clara melhora de vida de toda a população brasileira nesse período se forem levados em conta os dados apresentados, pois tanto a queda da mortalidade infantil quanto o aumento da esperança de vida ao nascer se referem a uma melhora genérica. Tratase da possibilidade de viver mais anos ou simplesmente de viver mais de um ano de vida (no caso da mortalidade infantil). 


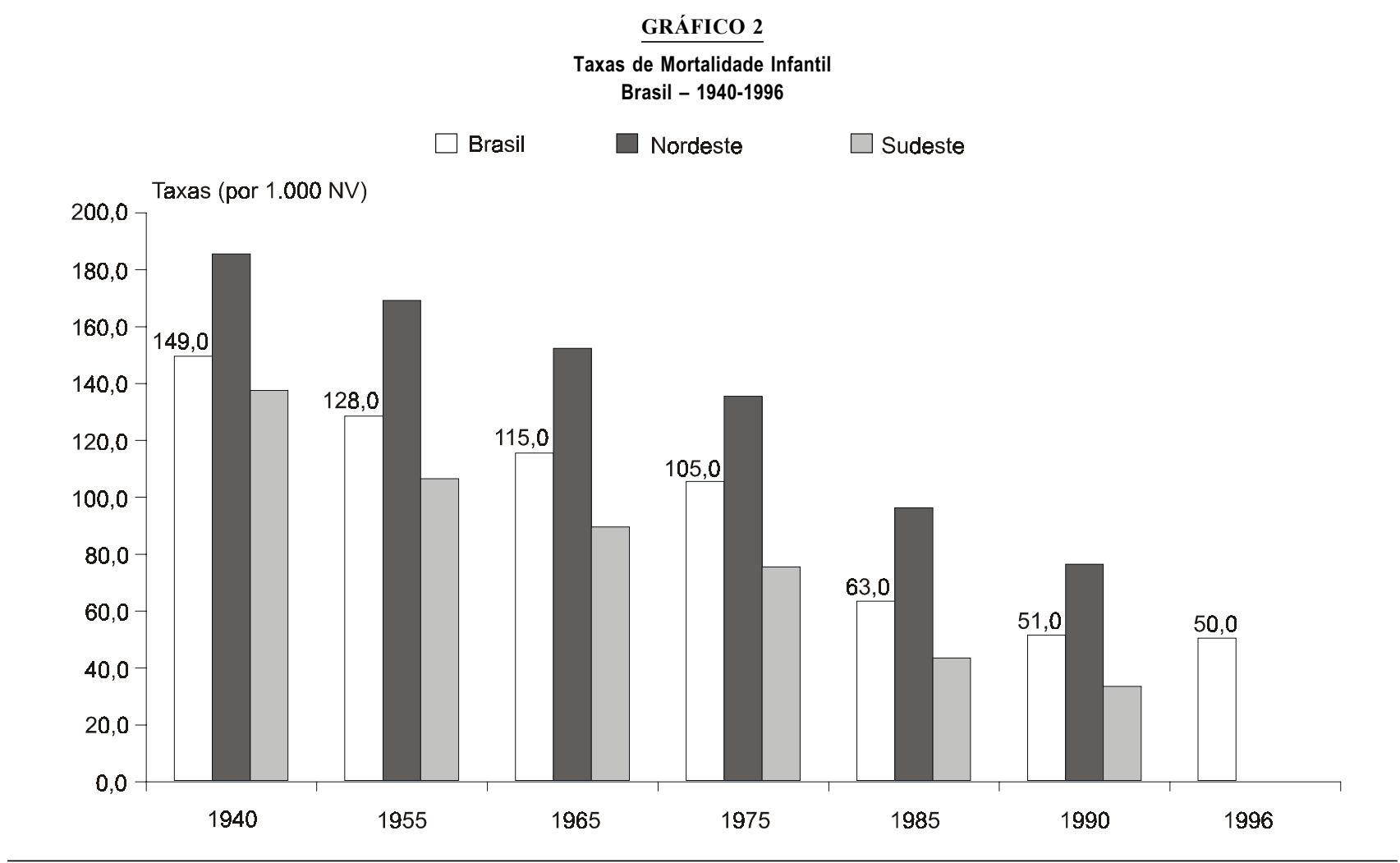

Fonte: Fundação IBGE.

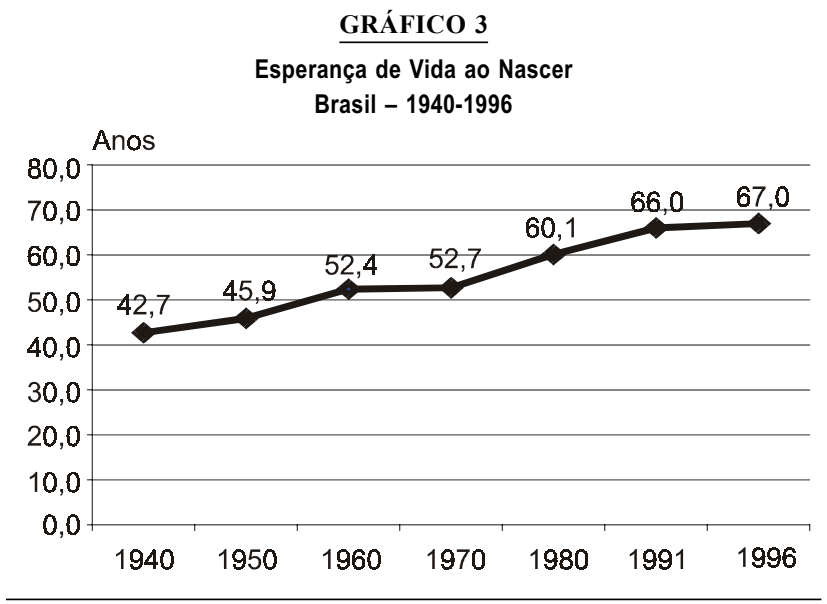

Fonte: Fundação IBGE; Banco Mundial.

Não são necessários argumentos para relacionar a evolução desses indicadores ao processo maciço de urbanização. Alguns dos principais fatores orientadores dessa dinâmica são: socialização de informações, extensão do serviço de água potável, extensão dos serviços de vacinas, acesso a antibióticos, atendimento médico ao parto e à gestante, aumento da escolaridade, entre outras condições que são mais acessíveis em meio urbano.
Poderia então se afirmar, a partir desses dados, que a vida da população brasileira melhorou, de um modo geral, e que essa melhora está ligada ao processo de urbanização? Não. Essa afirmação não pode ser feita. Nas próximas páginas são apresentados outros indicadores que se referem à evolução de dados socioeconômicos e urbanísticos, de modo a evidenciar as contradições aludidas no início do texto.

\section{DADOS SOCIOECONÔMICOS}

O Brasil apresentou um crescimento econômico acelerado durante o período de 1940 a 1980 , sem entretanto modificar significativamente a forte desigualdade social, como já foi observado. O impacto do declínio econômico nas décadas de 80 e 90 sobre uma sociedade já desigual aprofundou a exclusão social.

O registro do Produto Interno Bruto (PIB) brasileiro, nos últimos 50 a 60 anos do século $\mathrm{XX}$, revela um crescimento notável da economia dos anos 40 aos 80 (média de $7 \%$ ao ano), seguidos das chamadas "décadas perdidas" anos 80 e $90-$, quando se constatou uma queda significativa do crescimento (média de 1,3\% ao ano nos anos 80 e $2,1 \%$ ao ano entre 1990 e 1998). 
Tomando-se o ano de 1940 como índice de base 100 para o PIB per capita, o ano de 1998 apresentaria um indicador quase cinco vezes maior (498), mesmo se fossem incluídas aí as "décadas perdidas" (Dieese). Em contraste com esse crescimento econômico, o salário mínimo - um indicador socioeconômico do poder aquisitivo da população, previsto na Constituição brasileira - decresceu quatro vezes no mesmo período, como mostram os dados. Tal crescimento econômico, que atribuiu ao Brasil a décima colocação entre os PIBs mundiais, não implicou, entretanto, um desenvolvimento humano genérico, como se viu.

Nas "décadas perdidas", o Brasil sofre o efeito da reestruturação produtiva internacional que atinge os países capitalistas centrais no início dos anos 70. O impacto dos ajustes de inspiração neoliberal em sociedades como as latino-americanas tem conseqüências bem mais dramáticas do que nos países centrais. $\mathrm{O}$ choque ocorre sobre uma base estrutural e historicamente desigual, em que o welfare state não passou de direitos para alguns, em que não aconteceu, portanto, o pleno emprego, em que a previdência social alcançou apenas uma parte da sociedade, base na qual a cidadania, enfim, foi restrita.

Nas décadas de 80 e 90, a concentração de renda se aprofundou, como mostra a Tabela 3 . Não se trata simplesmente de uma desigualdade trazida pela reestruturação produtiva e pelo recuo das políticas sociais como sucede em muitos países centrais. Trata-se do aprofundamento da desigualdade numa sociedade historicamente e tradicionalmente desigual. Paulo Arantes discorre sobre o uso do termo "brasilianização" para caracterizar a fratura social em sociedades capitalistas centrais (Arantes, 2000). Nossas características nos tornaram modelo... de desigualdade social. Nas décadas de 80 e 90, no Brasil, como em quase todo o mundo (excetuando os Estados Unidos, nos anos 90), aumentaram o desemprego, as relações informais de trabalho e a pobreza nas áreas urbanas. Mas é bastante diferente iniciar o processo de reestruturação produtiva a partir de uma base de pleno emprego ou de direi-

TABELA 3

Distribuição de Renda

Brasil - 1981-1995

\begin{tabular}{lcc} 
& & Em porcentagem \\
\hline Distribuição & 1981 & 1995 \\
\hline $50 \%$ Mais Pobres & 14,5 & 13,3 \\
$10 \%$ Mais Ricos & 44,9 & 47,1 \\
$1 \%$ Mais Ricos & 13,4 & 14,4 \\
\hline
\end{tabular}

Fonte: Dieese. tos universais relativamente extensivos ou de uma base na qual os direitos são privilégios de apenas alguns.

Um dos indicadores mais expressivos e definitivos da piora nas condições de vida urbana é o aumento da violência a níveis antes nunca vividos pelas metrópoles brasileiras. A taxa nacional de homicídios (número de homicídios para cada 100 mil habitantes) no final dos anos 90 é de 24,10, mas em São Paulo e no Rio de Janeiro ela é mais do que o dobro. Em 1998, a taxa de São Paulo era de 59, e a do Rio de Janeiro estava em 56. O aumento da violência está relacionado de maneira intrínseca às metrópoles. É a principal causa de morte de homens com idades entre 10 e 38 anos e já começa a afetar a expectativa de vida ao nascer da população masculina brasileira (Fundação Seade). No Rio de Janeiro, a esperança de vida ao nascer sempre foi maior do que na região nordestina, mas a quantidade de mortes por assassinato nesse Estado faz com que ambos os índices se aproximem: entre 1990 e 1995 a expectativa de vida de um homem brasileiro médio era de 63,61 anos; no nordeste era de 61,16 e no Rio de Janeiro ficou em 61,51 anos (Simões, 2000).

Esses fatos são muito recentes na história do Brasil. A violência social sempre foi característica das zonas rurais, consideradas atrasadas diante do universo urbano, que se pretende moderno. Dadas suas dimensões, trata-se de um fenômeno inédito na sociedade brasileira e desconhecido anteriormente aos anos 80. É justamente no início dessa década que tal fenômeno ganha expressão significativa, coincidindo com o primeiro impacto recessivo das "décadas perdidas", o que levou o país a mergulhar no desemprego. Para melhor entendê-lo, serão particularizados os dados enfocando a metrópole de São Paulo.

\section{DESEMPREGO E VIOLÊNCIA NA CIDADE DE SÃO PAULO}

Os Gráficos 4 e 5 mostram a evolução do desemprego e da violência - medida pelo número de homicídios - na cidade de São Paulo.

Não é o caso de nos alongarmos neste artigo a respeito das relações entre violência, tráfico de drogas, desemprego e desigualdade. Muito tem sido escrito sobre isso e diversas são as teorias que tentam desvincular a violência da pobreza (o que é correto), da desigualdade e do desemprego (o que não é). A referência aqui são as muitas pesquisas do Núcleo de Estudos sobre a Violência da USP. O que interessa neste texto é a relação entre violência, espaço metropolitano ilegal e exclusão. 


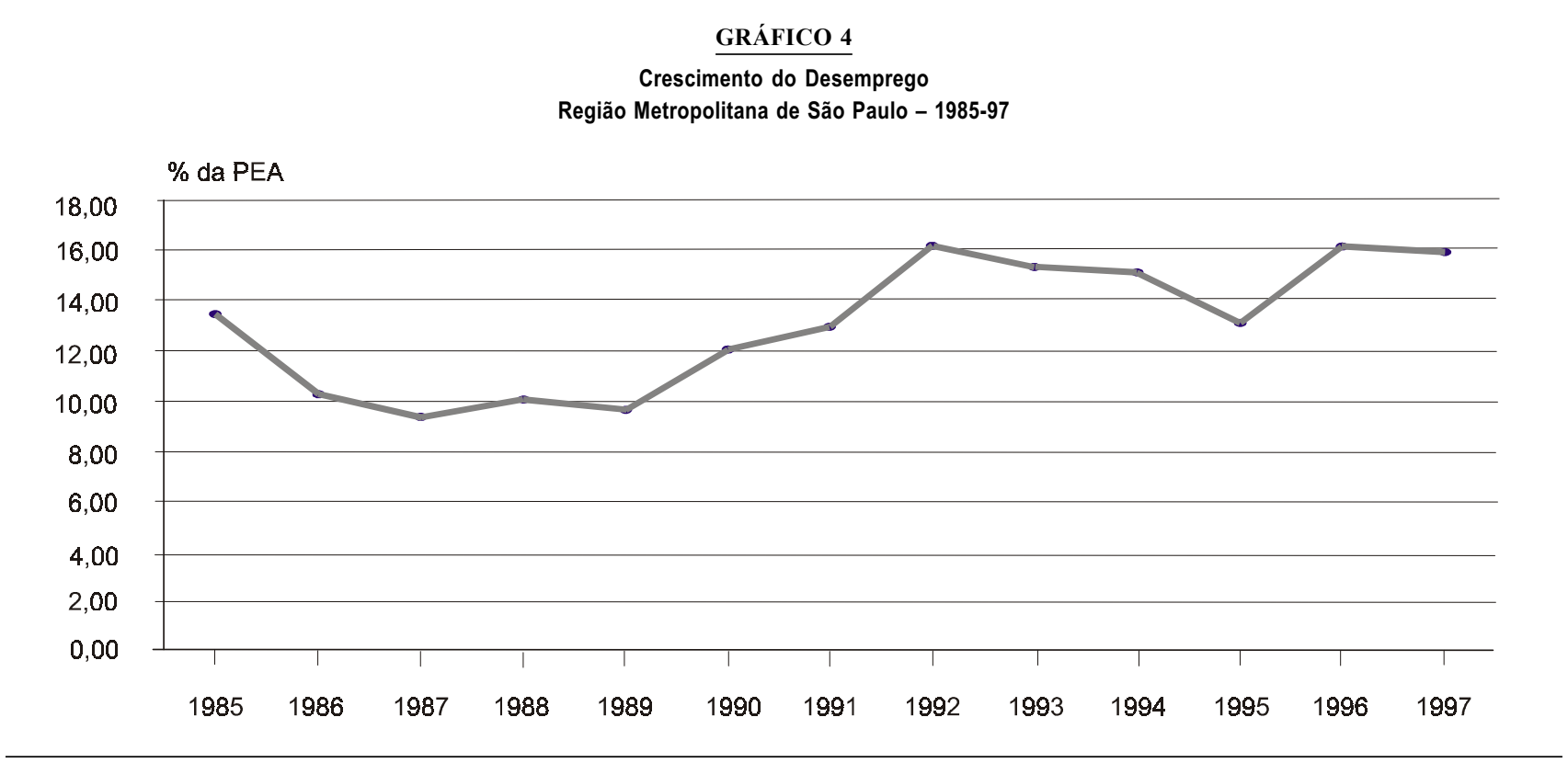

Fonte: Fundação Seade/Dieese.

Nota: Informações referentes aos meses de junho.

\section{GRÁFICO 5}

Aumento da Violência, segundo Taxa de Homicídios Município de São Paulo - 1960-1997

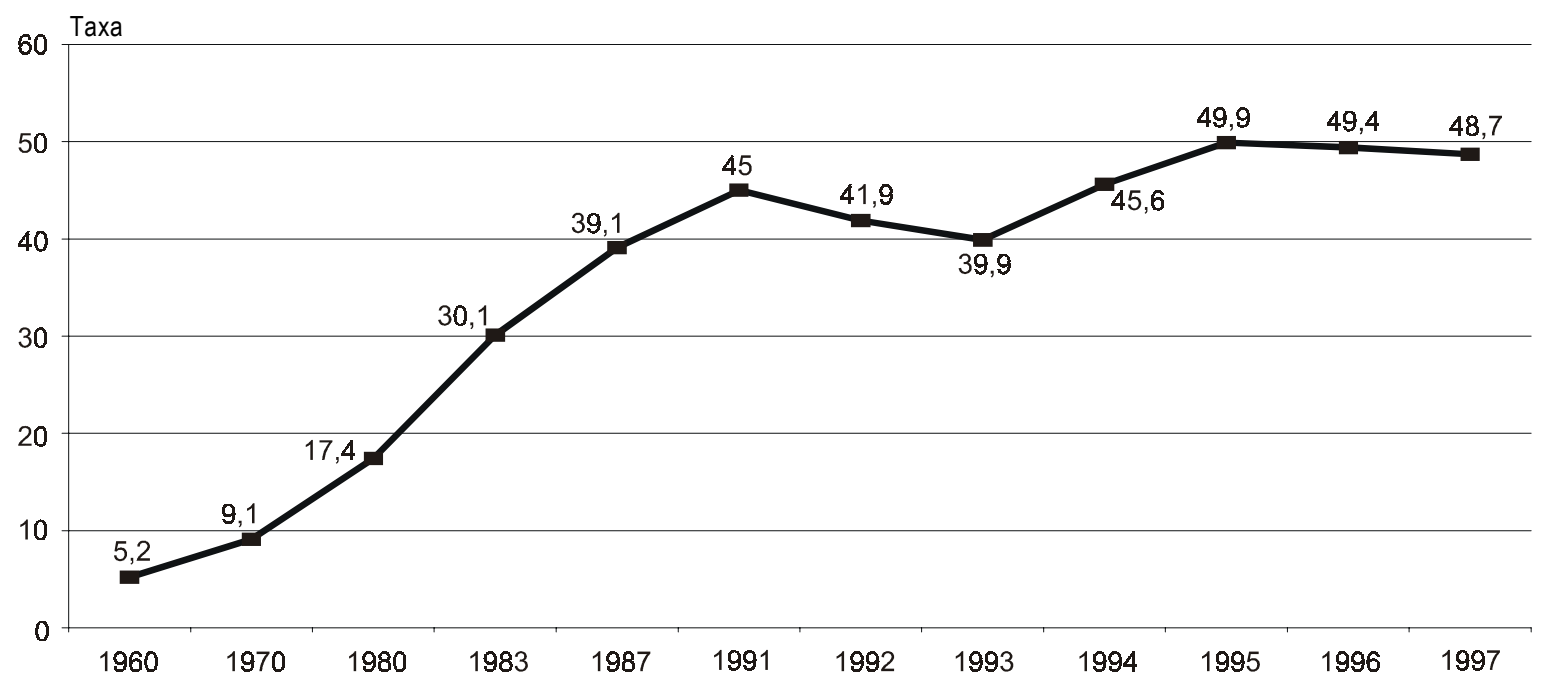

Fonte: Folha de S.Paulo/PRO-AIM.

Uma pesquisa de 1999 do Programa de Aprimoramento das Informações de Mortalidade do Município de São Paulo (PRO-AIM), organismo público municipal que registra as causas de morte na capital paulista, mostra de forma clara a relação entre a epidemiologia dos homicídios e as desigualdades sociais. Os dados do PRO-AIM, analisados por Marcos Drumond Júnior, evidenciam uma relação direta entre espacialidade e violência. As áreas mais violentas são aquelas em que predomina uma conjunção de determinados indicadores: níveis baixos de renda e escolaridade, maior proporção de negros entre os moradores, maior desemprego, maior número de moradores de favelas, piores condições de moradia e urbanísticas. 
Drumond elaborou um gráfico que relaciona o número mensal e a tendência dos homicídios com o território urbano dividido em quatro áreas socioambientais homogêneas. Na área de padrão de vida mais alto, o número de homicídios, que já era baixo em 1991, caminha em declínio até 1999. Na área socioambiental homogênea caracterizada pelas piores condições de vida, o número de homicídios começa alto em 1991 e apresenta uma linha acentuada de aumento conforme mostra o Gráfico 6. Ou seja, o aumento da violência em São Paulo entre 1991 e 1999, medido pelo número de homicídios, tem origem em alguns bairros e não em outros, evidenciando um quadro muito desigual.

O Morumbi, bairro de alto nível socioeconômico, constitui uma exceção, aparecendo entre os mais violentos no período. Mas o estudo mostra também que os assassinatos, nesse bairro, concentram-se em três favelas. Aliás, os dados apresentam uma forte correlação entre favelas e homicídios. Cinco regiões concentram 52\% dos homicídios entre 1994 e 1998. Nelas, a maior parte das mortes ocorreu em favelas. No Jardim Elisa Maria foram mortas 165 pessoas nesse período (Drumond Jr., 1999). Essa evidência é que nos permite afirmar que São Paulo, como outras metrópoles latino-americanas, cresce produzindo verdadeiras bombas socioecológicas no seu interior. Nessas cidades não há lei ou qualquer regulação, seja urbanística seja nas relações sociais.

Uma pesquisa do LABHAB-FAUUSP em favelas situadas em cinco cidades brasileiras evidencia um número

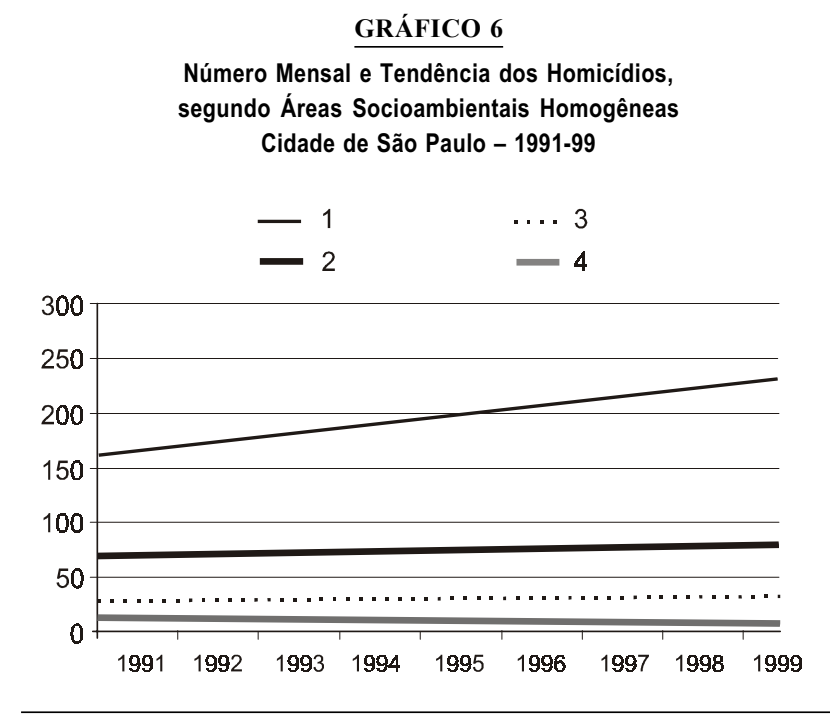

Fonte: PRO-AIM significativo de pessoas que permanecem ociosas a maior parte do tempo, no interior desses núcleos residenciais. ${ }^{3}$ Aí, em geral, o desemprego é maior, assim como é maior o número de pessoas por domicílio. Não se está longe da configuração de gueto que é reforçada pelo alto custo e pela baixa qualidade dos transportes.

A Companhia do Metropolitano de São Paulo realizou um levantamento que retrata a condição de mobilidade na metrópole paulistana, pela terceira década consecutiva 1977, 1987 e 1997. Essa pesquisa ajuda a consolidar a tese de que a vida na periferia urbana constitui um exílio, tal como a enunciou Milton Santos (1990). Cruzando o número de viagens a pé com a faixa de renda familiar, em 1997, verifica-se que, quanto maior a renda, menor é o número de viagens a pé. Nas faixas de renda inferiores (até $\mathrm{R} \$ 250,00$ ), mais da metade das viagens são feitas a pé. Isso quer dizer que, com exceção dos moradores dos cortiços em áreas centrais, os bairros de pior mobilidade são os dos moradores de baixa renda, situados na periferia longínqua. Nos bairros de boa qualidade ambiental e urbana, bem servidos de equipamentos e serviços, há menos viagens a pé do que nos bairros que não apresentam essas vantagens (Gráfico 7).

Concentração territorial homogeneamente pobre (ou segregação espacial), ociosidade e ausência de atividades culturais e esportivas, falta de regulação social e ambiental, precariedade urbanística, mobilidade restrita ao bairro, e, além dessas características todas, o desemprego crescente que, entre outras conseqüências, tende a desorganizar

\section{GRÁFICO 7}

Porcentagem de Viagens a Pé, por Faixa de Renda Média Familiar Região Metropolitana de São Paulo - 1997

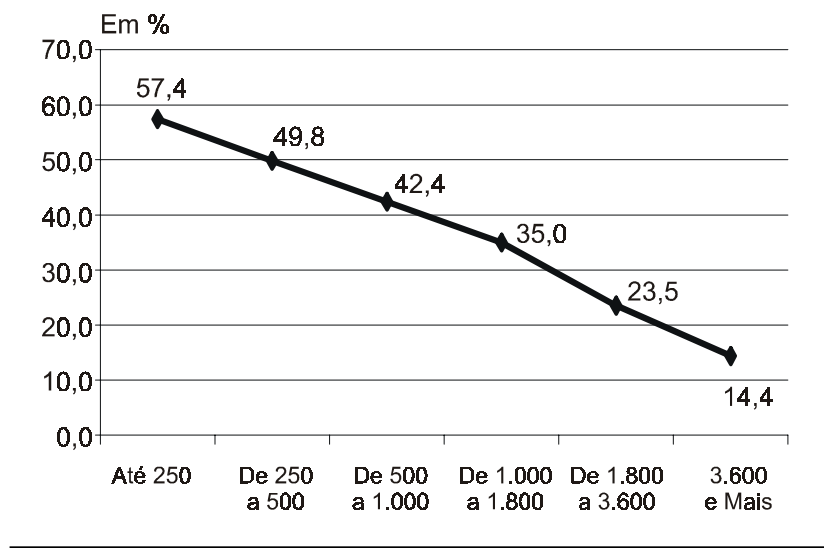

Fonte: Companhia do Metropolitano de São Paulo - Metrô. Nota: Em reais de outubro de 1997. 
núcleos familiares e enfraquecer a autoridade dos pais: essa é a fórmula das bombas socioecológicas. É impossível dissociar o território das condições socioeconômicas e da violência.

\section{ASPECTOS URBANÍSTICOS E AMBIENTAIS: A ECOLOGIA DA DESIGUALDADE ${ }^{4}$}

Apesar das características de diminuição do crescimento demográfico e da taxa de natalidade, é notável a dimensão da dinâmica de urbanização durante todo o século XX, como já foi destacado. Trata-se, entretanto, de uma gigantesca construção de cidades, parte dela feita fora da lei, sem a participação dos governos, sem recursos técnicos e financeiros significativos. Ou seja, é um imenso empreendimento, bastante descapitalizado e construído com técnicas arcaicas, fora do mercado formal.

Não há números gerais, confiáveis, sobre a ocorrência de favelas em todo o Brasil. Por falhas metodológicas ou ainda por uma dificuldade óbvia de conhecer a titularidade da terra sobre a qual as favelas se instalam, a Fundação IBGE, órgão responsável pelo censo demográfico anual, apresenta dados bastante subdimensionados. A busca de números mais rigorosos conduz a algumas prefeituras municipais, teses acadêmicas, centros universitários ou organismos públicos estaduais, que, entretanto, fornecem apenas dados pontuais.

A divulgação dos resultados iniciais do Censo IBGE de 2000 dá a entender que, entre 1991 e 2000, o número de favelas teria aumentado $22 \%$ em todo o Brasil, atingindo um total de 3.905 núcleos. Segundo o mesmo levantamento, o Município de São Paulo, que em 1991 apresentava 585 favelas, passa a registrar $612 \mathrm{em} 2000$. No entanto, levantamentos realizados pela Secretaria de Habitação e Desenvolvimento Urbano da Prefeitura de São Paulo, classificando a situação e a localização de cada núcleo de favela, revelavam a existência de 763 núcleos já em 1980, e 1.592 núcleos em 1987. O IBGE não contabiliza como favela núcleos que possuam menos de 50 unidades. Mas a diferença não se deve, simplesmente, a essa questão metodológica, embora algumas pesquisas mostrem que o número de núcleos com menos de 50 domicílios é expressivo. A maior dificuldade é identificar a situação fundiária dos assentamentos, já que nem mesmo muitos dos governos municipais têm esse conhecimento, que permitiria uma classificação rigorosa.

Segundo dados do Censo IBGE de 1991, Porto Alegre teria $7,89 \%$ da população morando em favelas. No entan- to, segundo dados de um censo realizado pela Prefeitura Municipal (DEMHAB), esse total é de $22,11 \%$ da população. Desses, $4,81 \%$ moram em favelas com menos de 51 domicílios.

Consultando diversas fontes, o LABHAB/FAUUSP reuniu dados estimados para a população moradora de favelas em algumas cidades brasileiras: Rio de Janeiro, 20\%; São Paulo, 22\%; Belo Horizonte, 20\%; Goiânia 13,3\%; Salvador, 30\%; Recife, $46 \%$; Fortaleza, $31 \%$. Os dados mostram um quadro que é impressionante sob qualquer critério. Mesmo considerando a precariedade da medição das moradias e do total da população residente em favelas, feita pelo IBGE, comparando os censos de 1980 e 1991 verifica-se que seu crescimento foi superior a $7 \%$ ao ano.

Mas o universo das favelas não esgota sua ilegalidade na ocupação do solo. Se a ele se somar o universo dos loteamentos ilegais, deve-se chegar à maior parte da população dos municípios de São Paulo e do Rio de Janeiro. Os números a respeito são, novamente, imprecisos e mesmo desconhecidos na maior parte das cidades brasileiras. A falta de rigor nos dados, que mostra o pouco interesse no conhecimento do tema, já é, por si, reveladora.

Em outras ocasiões apresentamos dados sobre a ilegalidade na ocupação do solo, uma máquina de produzir favelas e agredir o meio ambiente. O número de imóveis ilegais na maior parte das grandes cidades é tão significativo que, inspirados na interpretação de Arantes (1992) e Schwarz (1990) sobre Brecht, podemos repetir que "a regra se tornou exceção, e a exceção, regra". A cidade legal (cuja produção, pode-se dizer, é capitalista) caminha para ser, cada vez mais, espaço da minoria.

O direito à invasão é até admitido, mas não o direito à cidade. A ausência do controle urbanístico (fiscalização das construções e do uso/ocupação do solo) em certas áreas das cidades convive com sua "flexibilidade", dada pela pequena corrupção, na cidade legal. Legislação urbana detalhista e abundante, aplicação discriminatória da lei, gigantesca ilegalidade e predação ambiental constituem um círculo que se fecha em si mesmo.

Mas de todas as mazelas decorrentes desse processo de urbanização - no qual uma parte da população está excluída do mercado residencial privado legal e da produção formal da cidade - uma das mais graves talvez possa estar localizada na área de saneamento. Uma bem-sucedida política de expansão do acesso à rede de água tratada transformou positivamente, como visto anteriormente, os números relativos à mortalidade infantil. Porém, na dé- 
cada de 80 e especialmente nos anos 90 , houve um recuo nos investimentos em saneamento, quando o ciclo indispensável para universalizar o atendimento da população com água tratada não foi atingido e menos ainda o adequado destino do esgoto. Em 1998, 55\% dos domicílios no país não tinham acesso à água potável. Desses, 11,4 \% eram urbanos. Ainda no universo urbano, $48,9 \%$ dos domicílios não eram atendidos pela rede de esgotos. Segundo dados do governo federal, "apenas $24 \%$ do esgoto sanitário produzido pelos domicílios atendidos pelas 27 grandes companhias estaduais prestadoras de serviço de saneamento recebe tratamento, (...) apenas $15 \%$ do esgoto produzido nos domicílios brasileiros recebe tratamento e uma porcentagem ainda menor tem uma destinação final no meio ambiente sanitariamente adequada" (Presidência da República, 1998).

O destino das águas servidas e do esgoto, assim como de boa parte do lixo sólido produzido, fica evidente no desastroso comprometimento das redes hídricas, dos mananciais de água, das praias, dos mangues ou de qualquer outra localização nos arredores das cidades que não seja de interesse do mercado imobiliário.

\section{"DEFASAGEM E CONTEMPORANEIDADE" TAMBÉM NAS CIDADES}

Paralelamente a uma evolução altamente positiva em relação à mortalidade infantil, à esperança de vida ao nascer, à diminuição do crescimento demográfico e ao aumento da escolaridade, o processo de urbanização no Brasil apresenta, como se viu, a reprodução de novos e antigos males, nos indicadores de violência, pobreza, predação urbana e ambiental, poluição do ar e da água, etc.

Para a compreensão desse paradoxo, a análise pode ser orientada em dois rumos. O primeiro relaciona esse desenvolvimento urbano às características históricas de uma sociedade de raízes coloniais, que nunca rompeu com a assimetria em relação à dominação externa e que, internamente, nunca rompeu tampouco com a dominação fundada sobre o patrimonialismo e o privilégio. Como nota Caio Prado Jr., o proprietário privado se tornou poder político, econômico e social. O desenvolvimento das idéias liberais seria inviabilizado pela falta de autonomia entre essas esferas. O direito que a Coroa Portuguesa guardou sobre a terra foi apenas formal. O incrível atraso verificado nos registros de propriedades no Brasil - que permite a constante apropriação privada das terras devolutas ou a confusão, até nossos dias, sobre os limites das proprieda- des (que se verifica, por exemplo, em área de proteção dos mananciais em São Paulo) - é herança dessa característica (LABHAB, 2000).

A industrialização baseada em baixos salários determinou muito do ambiente a ser construído. Ao lado do grande contingente de trabalhadores que permaneceu na informalidade, os operários empregados do setor industrial não tiveram seus salários regulados pela necessidade de sua reprodução, com a inclusão dos gastos com moradia, por exemplo. A cidade ilegal e precária é um subproduto dessa complexidade verificada no mercado de trabalho e da forma como se processou a industrialização. Até mesmo parte dos trabalhadores empregados na indústria automobilística, surgida no Brasil nos anos 50, mora em favelas.

Vários autores brasileiros se detiveram em analisar as especificidades desse "desenvolvimento". Celso Furtado lhe atribui as características de defasagem e contemporaneidade; Francisco de Oliveira empresta de Trotski a construção do "desigual combinado". Florestan Fernandes lembra que se trata de "modernização com atraso" ou "desenvolvimento moderno do atraso". José de Souza Martins afirma a tese do "poder do atraso". Vanderley Guilherme conceitua essa construção social como "fratura institucional”. Várias são as análises que constatam a persistente preservação das oligarquias por meio de alianças políticas, durante as mudanças pelas quais passa o país ao longo de sua história: Independência (1822), República (1889), Revolução de 1930, Golpe de 1964, abertura democrática de 1986. No lugar dos direitos individuais persiste também a clássica relação de favor que, na esfera da política, implica trocas clientelistas, até mesmo nas metrópoles mais ricas. No campo, essa relação de favor, que marcou a vida do trabalhador branco pobre durante o período da escravidão, determina a filiação dos moradores a um latifundiário local. Estão entre os políticos mais importantes do país, nos anos 90, alguns chefes regionais, cujas famílias são hegemônicas em certos Estados brasileiros, especialmente nas regiões mais atrasadas. Apesar de muitas lutas, debates e até mesmo legislações aprovadas, relativos à reforma agrária, o latifúndio persiste incólume após quatro séculos.

Nesse contexto, no qual os direitos não são universais e a cidadania é restrita a poucos, deveria soar estranho o quadro jurídico, em geral bastante avançado. Entre a lei e sua aplicação há um abismo mediado pelas relações de poder na sociedade. É por demais conhecido no Brasil, inclusive popularmente, o fato de que a aplicação da lei 
depende de a quem ela (a aplicação) se refere. Essa "flexibilidade", que inspirou também o "jeitinho brasileiro", ajuda a adaptar uma legislação positivista, moldada sempre a partir de modelos estrangeiros, a uma sociedade em que o exercício do poder se ajusta às circunstâncias, e o que antes justificava um Estado forte, pode em seguida justificar seu contrário. É profundo o deslocamento entre a retórica e o real.

Esse paradoxo na aplicação da lei assume contornos mais complexos na cidade. Não se trata apenas de remeter para a ilegalidade parte da população que não tem acesso ao mercado formal. Há uma correlação entre lei (urbanística) e mercado imobiliário capitalista. O financiamento se aplica somente aos imóveis legais. A dificuldade no financiamento de imóveis populares, em todo o Brasil (caso da carta de créditos da Caixa Econômica Federal, em meados dos anos 90), deve-se à ilegalidade generalizada desses imóveis cuja documentação não corresponde às exigências do banco. Há portanto uma correlação entre financiamento e imóvel legal que termina por excluir grande parte da população do acesso a empréstimos destinados à aquisição ou construção de moradia.

Por outro lado, o controle urbanístico (a fiscalização sobre o uso e a ocupação do solo), de competência municipal, se dá somente na cidade legal. Para os assentamentos ilegais, em áreas que não interessam ao mercado imobiliário, a fiscalização é precária. Nem mesmo em áreas de proteção ambiental, sobre as quais incidem leis federais, estaduais e municipais, a fiscalização e a aplicação da lei ocorrem com mais rigor do que nas áreas valorizadas pelo mercado (o que não significa que haja o máximo rigor). Existe também, portanto, uma correlação entre mercado e gestão pública urbana. Mas essa relação vai mais longe. $\mathrm{O}$ mercado imobiliário visa aos investimentos públicos urbanos. Essa é a causa do investimento que justifica a sofisticação dos lobbies.

Essa cidade legal concentra também a maior parte dos investimentos públicos, já que ela se faz à imagem e semelhança das congêneres do Primeiro Mundo. $\mathrm{O}$ arbítrio acarreta uma tensão na aplicação da lei. A relação de favor reina soberana: na gestão, na regulação, nos pequenos investimentos na periferia, que obedecem à troca clientelista...

Numa análise que fizemos sobre o extinto Banco Nacional da Habitação (1964-1983) ficou evidenciada uma repartição do bolo dos recursos públicos (melhor seria chamá-los de semipúblicos) entre as empresas de construção pesada (obras de saneamento, urbanização) e em- presas de edificações (construção de conjuntos habitacionais). Os promotores imobiliários privados estavam satisfeitos em interferir sistematicamente na regulação dos recursos do SBPE (poupança privada) e da terra urbana. Completando esse quadro de interesses, os governantes distribuíam unidades habitacionais como parte da relação de troca ou favor (Maricato, 1987).

É claro que não podemos deixar de lembrar que muitas moradias foram construídas pelo $\mathrm{SFH}$, abrigando muita gente (2,4 milhões de unidades entre 1964 e 1986), mas o rumo poderia ter sido bem diferente: menos desperdício, impulsionando a cadeia produtiva para tecnologias mais adequadas, com políticas urbanas mais racionais, privilegiando a maioria da população.

O segundo rumo para o qual se tem dirigido a análise se concentra na natureza do mercado imobiliário privado legal, que deixa de fora mais da metade das populações urbanas. Nas cidades litorâneas em que a população trabalhadora local tem de disputar as terras com o mercado imobiliário de veraneio, a população excluída do mercado legal privado pode atingir mais de $80 \%$ do total, como é o caso do município de São Sebastião.

As políticas de promoção pública também não suprem essa imensa demanda. Na ausência de alternativa habitacional regular, a população apela para seus próprios recursos e produz a moradia como pode. As conseqüências desse universo de construção, completamente desregulado e ignorado pelo Estado, são trágicas, dadas suas dimensões. A maior parte dos governos municipais e estaduais desistiu de responder pelo "poder de polícia" sobre o uso e a posse do solo. A ocupação predatória e irracional resultante dessa falta de controle é a principal causa de uma lista grande de males, inaceitáveis em pleno início do século XXI: enchentes, desmoronamentos, poluição hídrica, epidemias, etc.

Apesar de o processo de urbanização da população brasileira ter se dado, praticamente, no século XX, ele conserva, como vimos, muitas das raízes da sociedade patrimonialista e clientelista próprias do Brasil pré-republicano. As resistências que, durante décadas, buscaram contrariar a abolição do trabalho escravo marcaram o surgimento do trabalho livre. A cidade é, em grande parte, reprodução da força de trabalho. Desde sempre, essa reprodução, entre nós, não se deu totalmente pelas vias formais, e sim pelos expedientes de subsistência. Essa característica marca decisivamente a produção das cidades. O patrimonialismo impediu o surgimento da esfera pública, alimentando o fisiologismo, o paroquialismo, o clien- 
telismo e o privilégio, possíveis, constatar até mesmo na Câmara Municipal da mais poderosa cidade brasileira em pleno ano 2000. A relação de favor tem mais prestígio do que as diretrizes de qualquer plano holístico.

\section{NOTAS}

1. Plínio de Arruda Sampaio Júnior analisa, em sua tese de doutorado, as dificuldades da construção da nação brasileira a partir de três autores brasileiros que rejeitam interpretações dos centros hegemônicos - Caio Prado Júnior, Florestan Fernandes e Celso Furtado (Sampaio Jr., 1999).

2. Ver a respeito Pamplona; Mautnner e Maricato (no prelo) sobre o consumo de objetos e a moradia em favelas, cortiços e loteamentos ilegais de São Paulo.

3. Ver a respeito a pesquisa Parâmetros para urbanização de favelas, financiada pela Finep e CEF, que teve a minha coordenação geral e a coordenação executiva de Laura Machado de Mello Bueno (LABHAB - FAUUSP, 1999). Ver ainda a tese de doutoramento de Bueno (2000).

4. As idéias que seguem foram desenvolvidas em Maricato, 1999 e 2000.

\section{REFERÊNCIAS BIBLIOGRÁFICAS}

ARANTES, P.E. Sentimentos da dialética. São Paulo, Paz e Terra, 1992. "A desordem do progresso". Revista Tiers Monde, 2000, no prelo.

ARANTES, O.; MARICATO, E. e VAINER, C. A cidade do pensamento único: desmanchando consensos. Petrópolis, Vozes, 2000.

ARRIGHI, G. A ilusão do desenvolvimento. Petrópolis, Vozes, 1997.

BORJA, J. e CASTELLS, M. Local y global. Madri, United Nations for Human Settlements/Taurus/Pensamiento, 1997.

BUENO, L.M. de M. Projeto e favela: metodologia para projetos de urbanização. Tese de Doutorado. São Paulo, FAUUSP, 2000.

CASTELLS, M. Imperialismo y urbanizacion en America Latina. Barcelona, Gustavo Gili, 1973.

CASTRO, M.C.P. de A explosão do cooperativismo habitacional em São Paulo, nos anos 90. Tese de Doutorado. São Paulo, FAUUSP, 1999.

CASTRO, M.C.P. de e SILVA, H.M.B. A legislação, o mercado e o acesso à habitação em São Paulo. São Paulo, LABHAB/FAUUSP, 1997.

DEBORD, G. La société du spetacle. Paris, Gallimard, 1992.

DRUMOND Jr., M. "Homicídios e desigualdades sociais na cidade de São Paulo: uma visão epidemiológica”. IV Congresso Paulista de Saúde Pública, Águas de Lindóia, 1999.

FERNANDES, F. Capitalismo dependente e classes sociais na América Latina. Rio de Janeiro, Zahar, 1975.

FURTADO, C. Formação econômica do Brasil. Rio de Janeiro, Paz e Terra, 1959.

HARVEY, D. A condição pós-moderna. São Paulo, Loyola, 1992.

LABHAB (Laboratório de Habitação e Assentamentos Humanos da FAUUSP). Parâmetros para urbanização de favelas. Rio de Janeiro, FINEP/CEF, 2000 (relatório de pesquisa).
MARCUSE, P. "The enclave, the citadel and the ghetto: what has changed in the post fordist U.S. city". Urban Affairs Review, Sage publications, v.33, n.2, nov. 1977.

MARICATO, E. A política habitacional do regime militar. Petrópolis, Vozes, 1987.

Habitação e as políticas fundiária, urbana e ambiental. Brasília, PNUD e Ministério das Relações Exteriores, 1995.

. Metrópole na periferia do capitalismo. São Paulo, Hucitec, 1996.

"Metrópole de São Paulo, entre o arcaico e a pós-modernidade". In: SOUZA, M.A. de et alii. Metrópole e globalização. São Paulo, Cedesp, 1999.

MARICATO, E.; ARANTES, O. e VAINER, C. A cidade do pensamento único. Petrópolis, Vozes, 2000.

MARTINS, J. de S. O poder do atraso: ensaios de sociologia da história lenta. São Paulo, Hucitec, 1994.

MORAES, A. de O. e ANTON, F.J. Mapa da irregularidade fundiária de Porto Alegre. Porto Alegre, Prefeitura do Município de Porto Alegre/DEMHAB, 2000.

MOREIRA, T.A. e COSTA NETO, J. de B. Preços de desapropriações de terras: limites às políticas públicas nas áreas de habitação, meio ambiente e vias públicas em São Paulo. São Paulo, LABHAB-FAUUSP e Lincoln Institute of Land Policies, 2000.

OLIVEIRA, F. de. "A economia brasileira: crítica à razão dualista". Cadernos CEBRAP, n.2. São Paulo, 1972.

PAMPLONA, T.; MAUTNNER, Y. e MARICATO, E. A apoteose dos contrastes. São Paulo, Fupam, no prelo.

PRADO Jr., C. História econômica do Brasil. São Paulo, Brasiliense (1945), 1990.

PRESIDÊNCIA DA REPÚBLICA. Diagnóstico dos serviços de água e esgotos. Brasília, Secretaria Especial de Desenvolvimento Urbano, 1998.

RIBEIRO, L.C. de Q. Dos cortiços aos condomínios fechados. Rio de Janeiro, Civilização Brasileira, 1997.

SAMPAIO Jr., P. de A. Entre a nação e a barbárie: os dilemas do capitalismo dependente. Petrópolis, Vozes, 1999.

SANTOS, M. Metrópole corporativa fragmentada. São Paulo, Nobel, 1990. . A urbanização brasileira. São Paulo, Hucitec, 1993.

SANTOS, W.G. dos. Razões da desordem. Rio de Janeiro, Rocco, 1993.

SCHWARZ, R. “As idéias fora do lugar”. Estudos Cebrap, n.3. São Paulo, Cebrap, 1973.

Um mestre na periferia do capitalismo. Machado de Assis. São Paulo, Duas Cidades, 1990.

SILVA, H.M.B. Terra e moradia: que papel para o municipio? Tese de Doutorado. São Paulo, FAUUSP, 1998.

SIMÕES, A de G. A mortalidade no Rio de Janeiro e seus efeitos na redução da sobrevivência masculina. Dissertação de Mestrado. Rio de Janeiro, Universidade Federal Fluminense, 2000.

SNAI. "Habitação e desenvolvimento urbano". Em Destaque. São Paulo, Secretaria Nacional de Assuntos Institucionais do PT, n.6, ago. 1996.

SOUZA, A.M.G. de. Invasões e intervenções públicas: uma politica de atribuição espacial em Salvador. Rio de Janeiro, IPPUR/UFRJ, 1990. 